\title{
The periodontal pain paradox: Difficulty on pain assesment in dental patients (The periodontal pain paradox hypothesis)
}

\author{
Haryono Utomo, ${ }^{*}$ Indah Listiana Kriswandini* and Diah Savitri Ernawati** \\ * Department of Oral Biology \\ ** Department of Oral Medicine \\ Faculty of Dentistry Airlangga University \\ Surabaya - Indonesia
}

\begin{abstract}
In daily dental practice, the majority of patients' main complaints are related to pain. Most patients assume that all pains inside the oral cavity originated from the tooth. One particular case is thermal sensitivity; sometimes patients were being able to point the site of pain, although there is neither visible caries nor secondary caries in dental radiograph. In this case, gingival recession and dentin hypersensitivity are first to be treated to eliminate the pain. If these treatments failed, pain may misdiagnose as pulpal inflammation and lead to unnecessary root canal treatment. Study in pain during periodontal instrumentation of plaque-related periodontitis revealed that the majority of patients feel pain and discomfort during probing and scaling. It seems obvious because an inflammation, either acute or chronic is related to a lowered pain threshold. However, in contrast, in this case report, patient suffered from chronic gingivitis and thermal sensitivity experienced a relative pain-free sensation during probing and scaling. Lowered pain threshold which accompanied by a blunted pain perception upon periodontal instrumentation is proposed to be termed as the periodontal pain paradox. The objective of this study is to reveal the possibility of certain factors in periodontal inflammation which may involved in the periodontal pain paradox hypothesis. Patient with thermal hypersensitivity who was conducted probing and scaling, after the relative pain-free instrumentation, thermal hypersensitivity rapidly disappeared. Based on the successful periodontal treatment, it is concluded that chronic gingivitis may modulate periodontal pain perception which termed as periodontal pain paradox
\end{abstract}

Key words: periodontal pain paradox, dental pain assessment

Correspondence: Haryono Utomo, c/o: Bagian Biologi Oral, Fakultas Kedokteran Gigi Universitas Airlangga. Jln. Mayjend. Prof. Dr. Moestopo 47 Surabaya 60132, Indonesia. Telp. 62 (31) 5053195. E-mail: dhoetomo@ indo.net.id

\section{INTRODUCTION}

Pain is categorized as physiological and clinical. In addition, clinical pain consisted of inflammatory and neuropathic pains. ${ }^{1}$ Modulation of clinical pain perception in individuals could be from central nervous system, that is suppressed transmission and facilitated transmission. Hyperalgesia refers to an increase in sensitivity to stimulation at the site of pain. Primary hyperalgesia occurs as the result of a lowered pain threshold or sensitization in the peripheral structures presumably due to the presence of algogenic substances or pro-inflammatory mediators. ${ }^{2}$

Periodontal pockets are source of subgingival biofilm and function as reservoir of periopathogenic Gram negative bacteria, including prevotella intermedia, porphyromonas gingivalis and Actinobacillus actinomycetecomitans. They are also the source of pro-inflammatory mediators in the periodontal tissues, which may lower the pain threshold of nociceptors. 2,3 Concerning pain during periodontal treatment, there is a study in probing and scaling procedures to patients who treated for plaque-related periodontitis. The study revealed that subgingival instrumentation causes in pain and discomfort. ${ }^{4}$

In some cases, gingivitis or chronic periodontitis patients may experience a strange pain sensation which proposed as a periodontal pain paradox. It could be explained as a contradiction in pain perception; the noxious stimulation such as periodontal probing may not elicit pain; in contrary, non-noxious stimulation such as rinsing with tap water resulting in the opposite. Despite the literatures discussed about pain and inflammation, the possible mechanism of the proposed periodontal pain paradox was rarely discussed. Presumably because it was thought to be a dentinal hypersensitivity and treated successfully with particular toothpaste which also improve periodontal health thus eliminating the pain symptoms.

The objective of this case report is to reveal the possible mechanism that occurs in the periodontal pain paradox and substances which involved in pain modulation.

\section{CASE}

A 53 years female came to a private dental practice, her main complaint was pain upon hot and cold stimulation in the lower right region, in which the cold stimulus gave more painful sensation. Rinsing with room temperature tap water also elicit pain even though it had a lower intensity than cold stimulation. She was able to point the exact location of pain, that was the lower right region. Nevertheless, 
previous dental treatment that was done on the right lower molar tooth made no improvement.

Extra oral inspection seemed normal. Intraorally, there was a temporary filling in mesial of 46 , the suspected source of pain. The interdental space between 46 and 45 was dark red and bleed easily upon probing. Rinsing with room temperature tap water elicit sudden and diffuse pain. However, pulpal thermal test with ethyl chloride on 46 and 45 did not show any pain. In other regions there were also mild periodontitis without gingivitis.

Periapical radiograph in 4645 did not reveal significant alveolar resorption and an overhanging filling on 45 . The overhanging filling was suspected to be the cause of the symptoms.

\section{CASE MANAGEMENT}

At first visit, the first thing to be done was reshaping the overhanged filling, followed by periodontal instrumentation. Preceding the periodontal instrumentation, that were scaling and probing procedures, the suspected area was irrigated with hexetidine $0.1 \%$, after 30 second, the procedures started. As pain sensation could also be felt by the patient. Anticipation was conducted by telling her to raise her left hand if sharp pain appeared. Deep scaling along the subgingival area, especially in the interdental space between 46 and 45 resulted in bleeding. Despite the bleeding, it seemed to be a paradox since the patient still comfortable and did not feel pain during this procedure.

After the periodontal instrumentation had finished, the patient was told to rinse with room temperature tap water; at that time she did not feel pain anymore. In order to give more confidence to the patient for the successful result, she was given ice water for rinsing; surprisingly it did not elicit pain either. Patient was scheduled for the next visit one week later

Second visit, the patient said that the pain symptom was completely disappeared. Intraorally, the gingival area which previously inflamed was pink-colored and not easily bleeds. Scaling procedures and probing which were done at the second visit felt more painful than the first visit. In order to maintain her periodontal health, she was told to floss her teeth regularly and had a routine dental check-up.

\section{DISCUSSION}

There are three kinds of pain receptors or nociceptors: a) mechanical nociceptor, b) thermal nociceptor, and c) polymodal nociceptor. Mechanical and thermal nociceptors transmitted the impulse created by stimulation faster $(12-18 \mathrm{~m} / \mathrm{sec})$ which dominates by the A- fibers than polymodal nociceptors which are the C-fibers $(0,5$ $\mathrm{m} / \mathrm{sec}$ ). Pricking or sharp sensation is mediated by the A- $\delta$, whereas burning sensation which is slightly delayed, by the C-fibers. It is known, however, that A- $\delta$ fibers also conduct touch, warm and cold, whereas C-fibers also conduct itch, warm, and cold. ${ }^{5,6}$

Nevertheless, the A-fibers dominate the cold sensation which is quickly felt as a sharp pain. The C-fibers also responsible for the diffuse and dull pain which experience shortly after the sharp pain. Polymodal nociceptors respond equally to all kinds of damaging stimuli, including irritating chemicals released from injured tissues. Despite their special characteristics, nociceptors do not have specialized receptor structures; they are all free nerve endings. 5,7

Each sensory receptor is attached to a first order or primary afferent neuron that carries impulses to the CNS. The axon of these first order neuron are found to have varying thickness, thicker fibers have faster conduction velocities. Pain receptors are also called nociceptors. ${ }^{5-7}$ Pain that are conducted by $\mathrm{A}$ and $\mathrm{C}$-fibers nociceptors can be sensitized by the presence of pro-inflammatory mediators and algogenic substances such as prostaglandin E2 (PGE2), bradykinin, nitric oxide (NO), histamine, serotonin etc. which cause primary hyperalgesia; or by repeated noxious stimulation (Figure 1). ${ }^{2,9-11}$

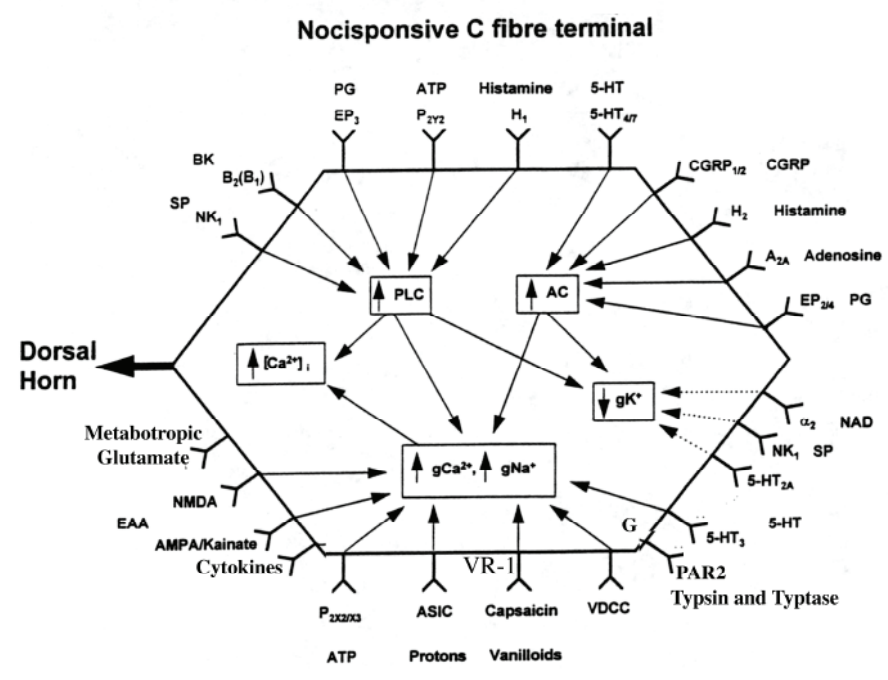

Figure 1. Pain receptors in free nerve ending. ${ }^{10}$ 


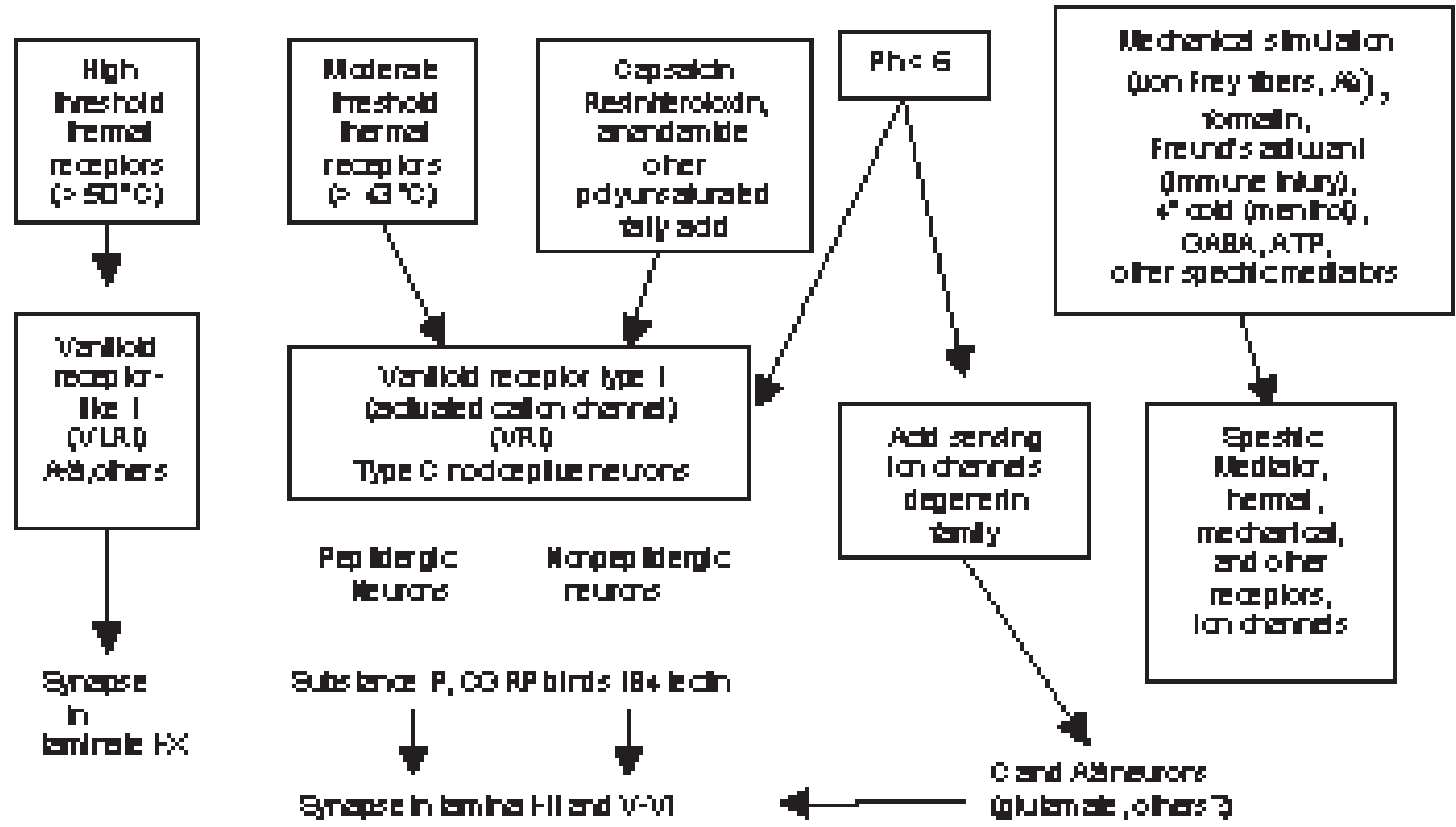

Figure 2. Nociceptive stimuli, nociceptive receptors, and subpopulation of type C neurons. ${ }^{12}$

The A-fibers, the thinly-myelinated fiber is rapidly activated and associated with acute pain. This is a good pain because it warns the host to take care of the problems, e.g. touching a hot saucepan. It also related with the glutamate neurotransmitter. The $\mathrm{C}$-fibers are unmyelinated, conduct impulses slowly; and associated with diffuse, dull, chronic pain. This is a bad pain because it cannot be alleviated simply by removing the stimulus. This pain is generated by such things as damaged tissue and cancer, and also related to the substance P neurotransmitter. ${ }^{2,8}$

Sensitized or stimulated afferent nerve fiber release neuropeptides that are substance $\mathrm{P}(\mathrm{SP})$ and calcitonin generelated peptide (CGRP) from their terminals. Substance $\mathrm{P}$ is slow to build up at the synapse and also slow to be destroyed, it is proposed as the result of the interplay between SP and CGRP.6,9 Substance P also able to enhance nociception, and this neurotransmitter can be released into the extracellular space. In addition, it is thought to be the major neurotransmitter in slow pain (e.g. deep, dull or aching sensation) which primarily carried by C-fibers. Glycine is a neurotransmitter which acts as the suppressor of pain transmission in the dorsal root ganglion, however, in inflammation prostaglandin potentiates the pain by blocking its action. Stimulation will be perceived as pain if exceeds a certain threshold of the receptors, which then transmit signals that the brain interprets as pain. ${ }^{2,6,7}$

Thermal sensation, pain elicited by heat or cold stimulation is perceived by different nerve fibers, cold perception is by the A- $\delta$ fibers which quickly response to cold stimulation. On the other hand, heat stimulation is perceived by the $\mathrm{C}$ - polymodal fibers which have the slower response. 5 There are several detectors or receptors of heat, cold and which are transmembrane proteins, embedded in the plasma membrane of the endings of sensory neurons. There are four heat receptors: 1) transient receptor potential vanilloid4 (TRPV4) -warm $\left(>25^{\circ} \mathrm{C}\right)$; 2) TRPV3 -warmer $\left(>31^{\circ} \mathrm{C}\right.$ ); 3 ) TRPV1 (also known as VR1) - hot $\left(>43^{\circ} \mathrm{C}\right)$, also activated by capsaicin, the active ingredient of hot chili peppers, and by acids (protons); 4) TRPV2 (also called VRL-1) - painfully hot (>50 ${ }^{\circ} \mathrm{C}$ ) (Figure 2). In addition, there are two cold receptors: 1) TRPM8 (or CMR1), is a channel that admits $\mathrm{Ca}^{2+}$ and $\mathrm{Na}^{+}$in response to moderate cold $\left(<28{ }^{\circ} \mathrm{C}\right)$ or menthol (the ingredient that gives mint its cool touch and taste) and 2) TRPA1 (or ANKTM1), responds to lower temperatures $\left(<18{ }^{\circ} \mathrm{C}\right)$ and elicit signals that the brain interprets at pain. $5,8,12$

According to a cross-sectional study, in patients suffered from chronic gingivitis only, the prostaglandin E2 has a greater quantity than gingivitis plus untreated periodontitis. ${ }^{13}$ The greater quantity of PGE2 may lower the pain threshold of the nociceptors to thermal changes which coincidence to this case report. Sensitization of nociceptors also occur from activation of kinases in the signaling pathway of the cytokines which present in abundant quantity in periodontal inflammation. $2,11,13$

Other pain modulators which involved in periodontal inflammation is bradykinin, which is a product of the kallikrein-kinin system. This system can be activated by mast cell tryptases and microbial proteinases, including gingipains. Gingipains, is a cysteine proteinase from porphyromonas gingivalis, the major pathogen of periodontal diseases, activates the kallikrein-kinin system through alternative cleavage of kininogens. This process subsequently produced bradykinin and kallidin. ${ }^{14,15}$ Prostaglandin E2 and bradykinin work in concert in lowering pain threshold of nociceptors. Bradykinin triggers an inflammatory positive feedback cycle, stimulating the release of prostaglandins and cytokines which in turn amplify the responsiveness of afferent nociceptors. In 
the presence of nitric oxide (NO) which is a product of macrophages during an inflammatory process, the lowered pain threshold is maintained. ${ }^{2}$

Since the patient complained about pain upon eating or drinking hot and cold water, it was suggested that rinsing with room temperature tap water which was a non-noxious (unharmful) stimuli and do not elicit pain. However, in this patient it caused a pricking pain; the sudden pain might be related to the lowered threshold of A- $\delta$ fibers which had faster impulse velocity than C-fibers. ${ }^{5}$ While previous treatment was intended to relieve pulpal inflammation, it seemed plausible that several visits of pulpal treatments were failed to alleviate the pain, because the main problem in this patient was related to periodontal inflammation, that was chronic gingivitis.

After deep scaling which surprisingly was a painless procedure in this patient, that also caused the inflamed gingiva to bleed; subsequently, the pain perception was back to normal. In order to evaluate the result of the treatment, the patient was told to rinse with tap water with room temperature, and followed by rinsing with ice water. Rinsing with the tap water did not elicit pain, and surprisingly, rinsing with ice water also gave the same result.

The possible explanation was that periodontal instrumentation removed the pro-inflammatory mediators (i.e. PGE2, bradykinin and NO), which responsible for lowering pain threshold were drained out from the inflamed gingiva. The exudates which came out accompanied by blood that oozed after the periodontal instrumentation also reduced the severity of chronic inflammation, and the gingival environment gradually returned to its normal condition.

Lipo polisaccharides were able to elicit pain in trigeminal nociceptor via the toll-like receptor-4 (TLR-4) and CD14 in dental pulp. ${ }^{16}$ Logically, in chronic gingivitis which involved the LPS and produces an array of proinflammatory mediators that may lower pain threshold should have a painful sensation. In contrary, in marginal periodontitis, a process associated with LPS is not generally reported as painful. Several hypothesis might explained this mechanism: 1) periodontal pathogenenic bacteria in marginal periodontitis might inactivate TLR/CD14 via released peptidases that are known to cleave receptors; 2) chronic LPS may induce a down-regulation in TLR4 expression, and in fact, a nine-fold reduction in TLR4 has been reported in marginal periodontitis; and 3) nociceptor innervations or function might differ in differing target tissues, such as dental pocket $v s$. periodontal pockets. ${ }^{16,17}$

Periodontal instrumentation, including scaling in probing may elicit pain and discomfort in patients, although it is also operator dependent. ${ }^{4}$ Nevertheless, in this case, the patient did not show any evidence of pain. The possibility was something blunted the pain stimulation to nociceptor which suspected to be the cleave of pain receptors by peptidases of the periodontal pathogenic bacteria. ${ }^{14}$

A possible explanation in this case is that peptidases from periodontal pathogenic bacteria cleave mechanoreceptor but not thermoreceptor, which resulted in blunted pain reception upon scaling and probing, whereas hot and cold sensation which are non-noxious become painful (compared to the other side of the mouth). In this case, the periodontal pain paradox suspected etiology was the lowered pain threshold which caused by the higher PGE2 level in chronic gingivitis compared to periodontitis. Sudden relief of pain symptoms occurred after scaling and drainage of pro-inflammatory mediators of the chronic gingivitis resulted from the normalizing pain threshold. Since the rapid resolution of inflammation in the gingiva also normalize the pain threshold, it concluded that chronic gingivitis, especially which bleed easily upon periodontal instrumentation is the main etiology of the periodontal pain paradox. However, further researches are needed to verify this hypothesis.

\section{REFERENCES}

1. Meliala. Terapi rasional nyeri: tujuan khusus nyeri neuropatik. $1^{\text {st }}$ ed. Jokyakarta: Aditya Media; 2004. p. 3.

2. Kidd BL, Urband LA. Mechanisms of inflammatory pain. Brit J Anaesth 2001; 87(1):3-11.

3. Li XJ, Kolltveit KM, Tronstad L, Olsen I. Systemic diseases caused by oral infection. Clin Microb Rev 2000; 13(4):547-58.

4. Steenberghe D, Garmyn P, Geers L, Hendrickx E, Marechal M, Huizar K, et al. Patients' experience of pain and discomfort during instrumentation in the diagnosis and non- surgical treatment of periodontitis. J Periodontol 2004; 75(11): 1465-70.

5. Squire LR, Bloom FE, McConnell SK, Roberts JL, Spitzer NC, Zigmond MJ. The Somatosensory sytem. In: Fundamental neuroscience. $2^{\text {nd }}$ ed. Orlando: Academic Press-Elsevier Science; 2003. p. 669-76.

6. Okeson JP. Bell's orofacial pain. $6^{\text {th }}$ ed. Carol Stream: Quintessence Pub; 2005. p. 262.

7. Sherwood L. Fundamentals of physiology. $1^{\text {st }}$ ed. Belmont: Thomson/ Brooks-Cole; 2006. p. 88, 147-8.

8. Kimball J. Heat, cold and pain. Available on line at: URL http:// users. rcn. com/ jkimball. ma. Ultranet/Biology/ pages/P/Pain. html. Accessed October 12, 2006.

9. Lundy W, Linden R. Neuropeptides and neurogenic mechanism in oral and periodontal inflammation. Crit Rev Oral Biol 2004; 15(2): 82-98.

10. Millan MJ. The Induction of pain: an integrative review. Neurobiol 1999; 57:1-16.

11. Moriyama T, Higashi T, Togashi K, Iida T, et al. Sensitization of TRPV1 by EP1 and IP reveals peripheral nociceptive mechanism of prostaglandins. Molecular pain 2005; 1(3):1-13.

12. Chih-Feng T, Baraniuk JN. Upper airway neurogenic mechanisms Cur Al Clin Immunol 2002; 2(1):11-9.

13. Burt B. Epidemiology of periodontal disease. J Periodontol 2005; 76:1406-19.

14. Deschner J, Singhal A, Long P, Liu CC, Piesco N, Agarwal S. Cleavage of CD14 and and LBP by a protease from prevotella intermedia. Arch Microbiol 2003; 179:430-6.

15. Imamura $T$, Potempa J, travis J. Activation of the kallikrein-kinin system and release of new kinins through alternative cleavage of kininogens by microbial and human cell proteinases. Biol Chem 2004; 385:989-96.

16. Wadachi R, Hargreaves KM. Trigeminal nociceptors express TLR-4 and CD14: a mechanism for pain due to infection. J Dent Res 2006; 85(1):49-53.

17. Muthukuru M, Jotwani R, Cutler CW. Oral mucosal endotoxin tolerance induction in chronic periodontitis. Infect immune 2005; 73:687-94. 